\title{
Differential targeting of protein kinase $B$ in cell death induced by sulindac and its metabolite sulindac sulfide
}

\author{
ANTHONY MAROTTA, KULJIT PARHAR, RAJINDER HUNDAL, VINCENT DURONIO* and BALJINDER SALH* \\ Department of Medicine, University of British Columbia, Jack Bell Research Center, \\ 2660 Oak Street, Vancouver, BC V6H 3Z6, Canada
}

Received November 24, 2005; Accepted January 18, 2006

\begin{abstract}
Non-steroidal anti-inflammatory drugs such as sulindac inhibit human colorectal carcinogenesis through a mechanism involving the direct inhibition of cyclooxygenase (Cox)-2. However, a wealth of recent evidence indicates that these agents might elicit their effects through mechanisms independently of Cox-2. In this study, we investigated the effects of sulindac and its metabolite, sulindac sulfide on modulation of the critical survival kinase, protein kinase $B$ (PKB). Here, we demonstrate for the first time that treatment with either sulindac or sulindac sulfide results in a decrease in PKB activity, and we provide compelling evidence that this occurs through two distinct mechanisms. Additionally, we report that overexpression of, and conditional activation of PKB attenuates the apoptotic effects of sulindac, but not for sulindac sulfide - the metabolic metabolite of sulindac. We also demonstrate that treatment with sulindac sulfide, but not sulindac, results in a very early robust activation of both caspase- 8 and -9 . Furthermore, we show that the apoptotic effects of sulindac sulfide can be reverted by both the caspase- 8 and -9 inhibitors. Evidence is provided to indicate that PKB is targeted by robust caspase activation due to sulindac sulfide. Hence, further investigation into the mechanisms regulating conversion of sulindac to sulindac sulfide (or direct use of the latter compound), may enhance our ability to target cancers with enhanced signaling through the growth factor $\rightarrow$ phosphatidylinositol 3-kinase pathway.
\end{abstract}

\section{Introduction}

Apoptosis (programmed cell death), is an important process that is required not only for ordered development, but also for maintaining tissue homeostasis (1-3). It has been suggested that

Correspondence to: Dr Baljinder Salh, Department of Medicine, Jack Bell Research Center, 2660 Oak Street, Vancouver, BC V6H 3Z6, Canada

E-mail: bsalh@interchange.ubc.ca

*Both senior authors contributed equally

Key words: apoptosis, non-steroidal anti-inflammatory drugs, protein kinase B, caspase activation malfunction or deregulation of this process may be important in the establishment or development of a number of diseases, including neurodegenerative disorders and cancer $(4,5)$.

There are at least two possible mechanisms through which a cell can become committed to undergo apoptosis; these differ primarily on the basis of where the apoptotic signal is generated. Apoptotic signals, which are triggered through the activation of cell surface receptors including members of the TNF receptor family, mediate their effects through a series of death domain containing proteins that ultimately lead to the activation of caspase- $8(6,7)$. The second apoptotic program can be initiated at the level of the mitochondria. This form of cell death involves the loss of mitochondrial integrity, the release of cytochrome $\mathrm{c}$ into the cytoplasm and the subsequent formation of the apoptosome complex consisting of Apaf-1, dATP, cytochrome $\mathrm{c}$ and caspase-9 (8-10).

It is well documented that both caspases- 8 and -9 impinge upon and mediate their effects through caspase-3. Caspase-3 is described as one of the executioners of apoptosis; its proteolytic targets include poly-ADP ribose polymerase (PARP), B-catenin, protein kinase $\mathrm{B}(\mathrm{PKB})$, and nuclear lamins amongst others (11-13). The onset of apoptosis is marked by a number of morphological changes including membrane blebbing, cell shrinkage, chromatin condensation and DNA fragmentation.

It is known that chemotherapeutic agents like 5-FU mediate their anti-neoplastic effects through the apoptotic network (14). In addition, a specific class of chemopreventive drugs known as the non-steroidal anti-inflammatory drugs (NSAIDs), which have been reported to cause regression of polyps in both humans and animals (15-17), is believed to primarily mediate its anti-neoplastic effects by inhibiting prostanoid biosynthesis at the level of cyclooxygenase (Cox)-2. However, a number of recent studies indicate that Cox-2-independent mechanism(s) are likely also involved in this process. In this regard, NSAIDs have been reported to alter the Bax:Bcl- $\mathrm{X}_{\mathrm{L}}$ ratio, to inhibit $\mathrm{NF}-\kappa \mathrm{B}$ signaling, to inhibit PPAR $\delta$, and to inhibit ILK signaling (18-21).

The ILK signaling network, which lies downstream of the PI3-kinase pathway, has received a great deal of attention for its roles in promoting cell growth and invasion as well as inhibiting apoptosis (reviewed in ref. 22). ILK is predominately believed to mediate its pro-survival effects through the oncogenic protein, $\mathrm{PKB} / v$-Akt. $\mathrm{PKB}$ can inhibit cell death in response to a number of apoptotic stimuli including growth 
factor withdrawal, UV irradiation, DNA damage, matrix detachment, cell cycle discordance and treatment of cells with either anti-Fas or TGFß antibodies (23). The precise mechanism by which PKB mediates its pro-survival effects however is not established. Putative PKB consensus phosphorylation sequences have been identified in a number of apoptosis-related proteins including Bad, Bcl-2, Apaf-1, caspases 7-9 and Forkhead transcription factors (23-26). Whether these are phosphorylated in vivo by PKB requires further characterization.

In this study, we report for the first time that sulindac and its metabolite, sulindac sulfide differentially target ILK and $\mathrm{PKB}$ in vitro as well as $\mathrm{PKB}$ in vivo. The latter is mediated by a robust caspase-mediated cleavage of the molecule.

\section{Materials and methods}

Materials. Rabbit polyclonal anti-PKB was kindly provided by Stressgen Biotechnologies Inc. (Victoria, BC). Histone H2B was obtained from Upstate Biotechnology Inc. (Lake Placid, NY). Anti-phosphospecific-PKB Ser473 was obtained from New England Biolabs Inc. (Beverly, MA). Horseradish peroxidase conjugated secondary rabbit and mouse antibodies, sulindac sulfide, sulindac sulfone, NS-398, caspase-8 (Z-IETDFMK) and caspase-9 (Z-LEHD-FMK) inhibitor and caspase-8, -9 and -3 substrate conjugated to AFC were obtained through Calbiochem (San Diego, CA). Sulindac, aspirin (ASA), cAMP-dependent protein kinase inhibitor peptide, EGTA, EDTA, MOPS, PMSF, sodium orthovanadate, leupeptin, aprotinin, benzamidine, dithiothreitol, ß-glycerolphosphate and propidium iodide were purchased from Sigma-Aldrich (Saint Louis, MO). The HA-PKB construct was obtained from Dr J. Woodgett (Ontario Cancer Institute, Toronto, Canada).

Cell culture. The human colon adenocarcinoma cell line DLD-1 was obtained from the American Type Culture Collection (Rockville, MD). The human colon cancer cell line HCT-116 was a gift from B. Vogelstein. DLD-1 cells were cultured in RPMI-1640 medium containing $2 \mathrm{mM}$ L-glutamine, $10 \mathrm{mM}$ HEPES, $1 \mathrm{mM}$ sodium pyruvate, $4.5 \mathrm{~g} / 1$ glucose supplemented with $10 \%$ fetal bovine serum. The HCT-116 cells were cultured in McCoys $5 \mathrm{~A}$ media containing $1 \%$ penicillin/streptomycin supplemented with $10 \%$ fetal bovine serum. HEK-293 cells were a gift from Dr Alice Mui. These cells were cultured in Dulbecco's minimum essential medium (DMEM) containing $10 \%$ fetal bovine serum and $1 \%$ penicillin/streptomycin and L-glutamine (2 mM). PKB-ER MC/9 cells were grown in RPMI-1640 medium containing 10\% FBS, 2 mM L-glutamine, $1 \mathrm{mM}$ sodium pyruvate, $20 \mu \mathrm{M}$ 2-mercaptoethanol, and $10 \%$ WEHI-3 conditioned medium as a source of IL-3. All cells were culture in a humidified chamber at $37^{\circ} \mathrm{C}$ in $5 \% \mathrm{CO}_{2}$. $\mathrm{MC} / 9-\mathrm{PKB}-\mathrm{ER}$ cells were prepared using retroviral infection of MC/9 cells with PMX-Puro containing the PKB-ER fusion construct, which was a kind gift from Dr Richard Roth (27).

SDS-polyacrylamide gel electrophoresis. Protein samples for immunoblotting were resolved using sodium dodecylsulphatepolyacrylamide gel electrophoresis (SDS-PAGE). Proteins were transferred onto the nitrocellulose membrane in a Bio-Rad transfer apparatus and the nitrocellulose membrane was blotted with the appropriate antibody at a dilution of $1: 1000$ in $0.05 \%$ Tween-TBS. The resulting membrane was exposed to ECL for $1 \mathrm{~min}$. The Western blot was then exposed to film to visualize the immunoreactive proteins.

Enzymatic activation - inhibitor studies. DLD-1 and HCT116 cells were seeded at a density of $1 \times 10^{6}$ cells per $100 \mathrm{~mm}$ dish. Twenty-four hours after seeding, the cells were serum starved for $16 \mathrm{~h}$ and pre-treated with the appropriate NSAID for an additional $2 \mathrm{~h}$. Following this, the cells were stimulated with $10 \%$ FBS for $10 \mathrm{~min}$ in either the presence or the absence of the drug and rinsed once with ice-cold PBS. The PBS was aspirated off and the cells were harvested in $1 \mathrm{ml}$ of homogenization buffer (20 mM MOPS, $50 \mathrm{mM}$ ß-glycerolphosphate, $50 \mathrm{mM}$ sodium fluoride, $1 \mathrm{mM}$ sodium vanadate, 5 mM EGTA, 2 mM EDTA, 1\% NP40, 1 mM dithiothreitol, $1 \mathrm{mM}$ benzamidine, $1 \mathrm{mM}$ phenylmethanesulphonylfluoride and $10 \mu \mathrm{g} / \mathrm{ml}$ leupeptin).

Immunoprecipitation. The appropriate lysate $(400 \mu \mathrm{g})$ was incubated with $4 \mu \mathrm{g}$ of anti-PKB (Stressgen Bio-technology Corp., Victoria, Canada) overnight at $4^{\circ} \mathrm{C}$ with gentle mixing. To each vial, $30 \mu 1$ protein A Sepharose was added for an additional $1 \mathrm{~h}$ at $4^{\circ} \mathrm{C}$. The lysates were then centrifuged and the supernatent was discarded. The protein A Sepharose beads conjugated to the antibody were washed twice with the standard lysis buffer and twice with protein kinase reaction buffer (100 mM HEPES pH 7.0, $20 \mathrm{mM} \mathrm{MgCl}_{2}$, $2 \mathrm{mM} \mathrm{MnCl}_{2}$, and $2 \mathrm{mM} \mathrm{Na}$ orthovanadate).

Immune complex kinase assays. The beads were pelleted and the reaction was started by the addition of $25 \mu 1$ of the kinase reaction buffer (50 mM HEPES pH 7.0, $10 \mathrm{mM} \mathrm{MgCl}{ }_{2}, 1 \mathrm{mM}$ $\mathrm{MnCl}_{2}$, and $1 \mathrm{mM} \mathrm{Na}$ orthovanadate, $2 \mathrm{mM} \mathrm{NaF}, 5 \mu \mathrm{g}$ of the appropriate substrate per tube and $0.5 \mu \mathrm{g}$ of ATP $(250 \mu \mathrm{M}$ ATP, $\left.1 \mu \mathrm{Ci}\left[\gamma^{3}{ }^{32} \mathrm{P}\right] \mathrm{ATP}\right)$ at $30^{\circ} \mathrm{C}$ for $20 \mathrm{~min}$. The reaction was terminated with the addition of $10 \mu 1$ of $4 \mathrm{X}$ sample buffer. The tubes were centrifuged for $1 \mathrm{~min}$ and the proteins were separated on a $14 \%$ SDS-PAGE gel. The resulting gel was stained with Coomassie Blue and then dried. The phosphorylation of the HH2B substrate was visualized by autoradiography and quantitated by densitometry using the Bio-Rad Gel Doc system.

In vitro kinase assays. The appropriate recombinant protein enzyme kinases (rILK or rPKB) $(10 \mu 1)$ diluted in assay dilution buffer was incubated with varying dosages of either sulindac or sulindac. To each tube, $10 \mu 1$ of the appropriate substrate was added. The reaction was initiated with the addition of $5 \mu 1$ of $\left[\gamma^{-32} \mathrm{P}\right]-\mathrm{ATP}$ and incubated at $30^{\circ} \mathrm{C}$ for $10 \mathrm{~min}$. Subsequently, $10 \mu \mathrm{l}$ of the reaction mixture was spotted onto a P81 Whatman filter paper and washed three consecutive times with $1 \%$ phosphoric acid for 10 min each. Enzymatic activity was assessed by scintillation counting as outlined above.

Overexpression studies. To assess the influence of PKB on cell viability in response to sulindac and sulindac sulfide, 
cells were transiently transfected with the appropriate plasmid using Effectene. A total of $1 \mu \mathrm{g}$ of plasmid cDNA was added to each $60 \mathrm{~mm}$ dish in $5 \mathrm{ml}$ of the appropriate cell culture medium. The cells were left for $8 \mathrm{~h}$ at $37^{\circ} \mathrm{C}$ in a $5 \% \mathrm{CO}_{2}$ incubator. After this period, the medium containing the DNA-Effectene complexes was removed and $5 \mathrm{ml}$ of new medium was added. The cells were incubated for an additional $24 \mathrm{~h}$ to allow for gene expression. The efficiency of transfection was determined by co-expression of GFP.

MTS cell viability assay. To assess the effects of non-steroidal anti-inflammatory agents on cell viability, the colorimetric MTS method from Promega was utilized. Briefly, cells were treated with the appropriate drug for a 24-h interval in the presence of $1 \%$ serum containing medium. At $22 \mathrm{~h}, 20 \mu \mathrm{l}$ of the MTS/PMS (333 $\mu \mathrm{M} / 25 \mu \mathrm{M})$ solution was added to $100 \mu \mathrm{l}$ of the appropriate culture medium in a 96-well plate for $2 \mathrm{~h}$ in a humidified chamber at $5 \% \mathrm{CO}_{2}$ and $37^{\circ} \mathrm{C}$. The absorbance was measured at $490 \mathrm{~nm}$ using an ELISA plate reader. The absorbance reading is directly proportional to the number of viable cells.

For the caspase inhibitor studies, cells were pre-treated with $1 \%$ FBS media containing $100 \mu \mathrm{M}$ of either $\mathrm{z}$-VAD-fmk, z-IETD-fmk or z-LEHD-fmk inhibitor for $1 \mathrm{~h}$. Following pre-incubation, $50 \mu 1$ of a $2 \mathrm{x}$ drug containing solution was added to the original $50 \mu$ l, to achieve a final caspase inhibitor concentration of $50 \mu \mathrm{M}$. Viability was assessed as outlined above.

PI staining and FACS analysis. The PKB-ER cells were treated with either sulindac or sulindac sulfide in the presence or absence of $1 \mu \mathrm{M} 4$-HT for $24 \mathrm{~h}$. Subsequently the cells were harvested, collected by centrifugation, and fixed in $70 \%$ ethanol overnight at $4^{\circ} \mathrm{C}$. On day 3 , the cells were pelleted and resuspended in phosphate-buffered saline containing $0.1 \%$ glucose, $100 \mu \mathrm{g} / \mathrm{ml} \mathrm{RNaseA}$, and $50 \mu \mathrm{g} / \mathrm{ml}$ propidium iodide and left in the dark, at room temperature for $45 \mathrm{~min}$. The samples were analyzed using an EPICS XL flow cytometer (Coulter).

Caspase activity assays. Cells were seeded at a density of $1 \times 10^{5}$ per well in a 6 -well dish. Twenty-four hours later, the cells were deprived of serum for $16 \mathrm{~h}$ and then were either untreated or treated with sulindac or sulindac sulfide for the indicated times to measure caspase- $8,-9$ and -3 activity using the corresponding AFC-fluorogenic substrates. Briefly, adherent and non-adherent cells were collected, centrifuged and washed in ice-cold PBS. Subsequently, the cells were homogenized as outlined above and the protein levels were evaluated. For each reaction, $5 \mu \mathrm{g}$ of the fluorogenic substrate was added to approximately $100 \mu \mathrm{g}$ of total protein per condition. Liberation of AFC was detected using a spectrofluorometer with an excitation wavelength of $405 \mathrm{~nm}$ and an emission wavelength of $520 \mathrm{~nm}$.

Preparation of inhibitors. Sulindac was dissolved in Trisbuffer (pH 8.0) while ASA, sulindac sulfide, NS-398, caspase-8 and-9 were dissolved in DMSO. All inhibitors were diluted to the desired concentration with the appropriate cell culture medium.

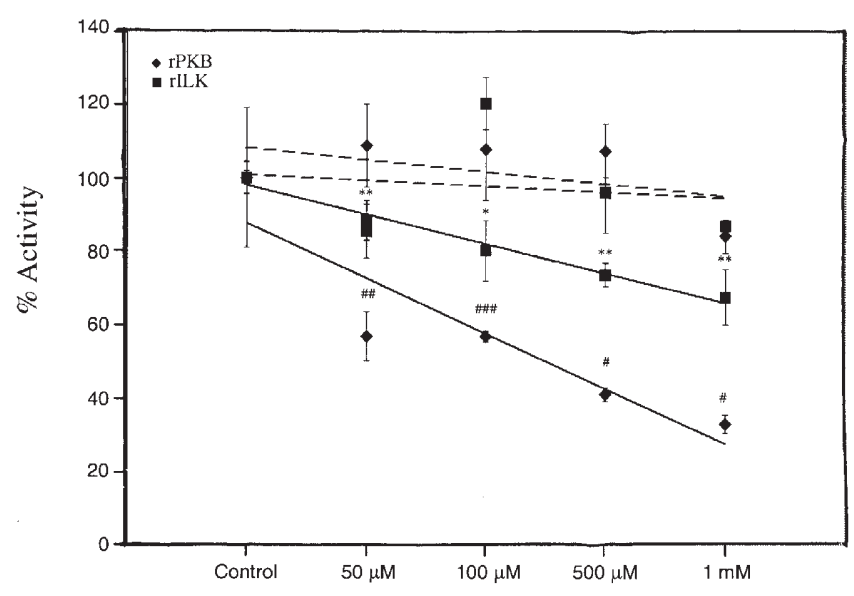

Figure 1. Effects of sulindac and sulindac sulfide on in vitro PKB activity. Recombinant ILK was assayed in the presence of varying dosages of either sulindac (-) or sulindac sulfide (---) using MBP as the substrate for a 20-min interval. Recombinant PKB was assayed in the presence of varying dosages of either sulindac (-) or sulindac sulfide (---) using HH2B as the substrate for a 10 -min interval $\left({ }^{*} \mathrm{p}<0.002,{ }^{* *} \mathrm{p}<0.005,{ }^{\#} \mathrm{p}<0.05,{ }^{\# \#} \mathrm{p}<0.01\right.$, $\mathrm{p}<0.0001)$. All experiments were performed in triplicate. The data are presented in a linear format for ease of interpretation of sulindac's effects over the indicated dose range.

Statistical analysis. Band densities were measured by scanning the film using the Bio-Rad gel-doc apparatus into a TIFF format file. The band densities and the results are expressed as mean $\pm \mathrm{SD}$, with $\mathrm{p}<0.05$ being considered significant using Student's t-test (unpaired, two-tailed).

\section{Results}

Effects of NSAIDS on biochemical activity of PKB. A variety of extracellular signals has been reported to activate the PI3kinase signaling nexus, such as insulin, EGF and PDGF (28). This nexus is known to play a pivotal role in preventing cell death (23), via the serine/threonine protein kinase, $\mathrm{PKB} / \mathrm{Akt}$. We have previously demonstrated that sulindac could inhibit the serum-induced activation of ILK. ILK is a putative PDK2 that has been reported to phosphorylate PKB on Ser473; phosphorylation at this critical serine residue in addition to Thr308 phosphorylation results in the activation of the latter (20). Based upon our earlier observations, we postulated that these agents might influence the biochemical activity of PKB in an ILK-dependent fashion. To initially explore this, we sought to investigate whether sulindac or the active metabolite of sulindac, sulindac sulfide, could modulate the biological activity of either ILK or PKB directly in vitro. We performed a series of in vitro protein kinase assays using either recombinant ILK or recombinant PKB in the presence of either sulindac or sulindac sulfide at equimolar concentrations (Fig. 1). The data from these studies revealed that sulindac could inhibit the biochemical activity of both ILK and PKB; however to our surprise PKB appeared to be more sensitive to the inhibitory effects of this agent. Intriguingly, no in vitro inhibitory effects were observed with the metabolite of sulindac, sulindac sulfide. Based upon this data, we concluded that sulindac but not sulindac sulfide directly targets both ILK and PKB in vitro. 
A

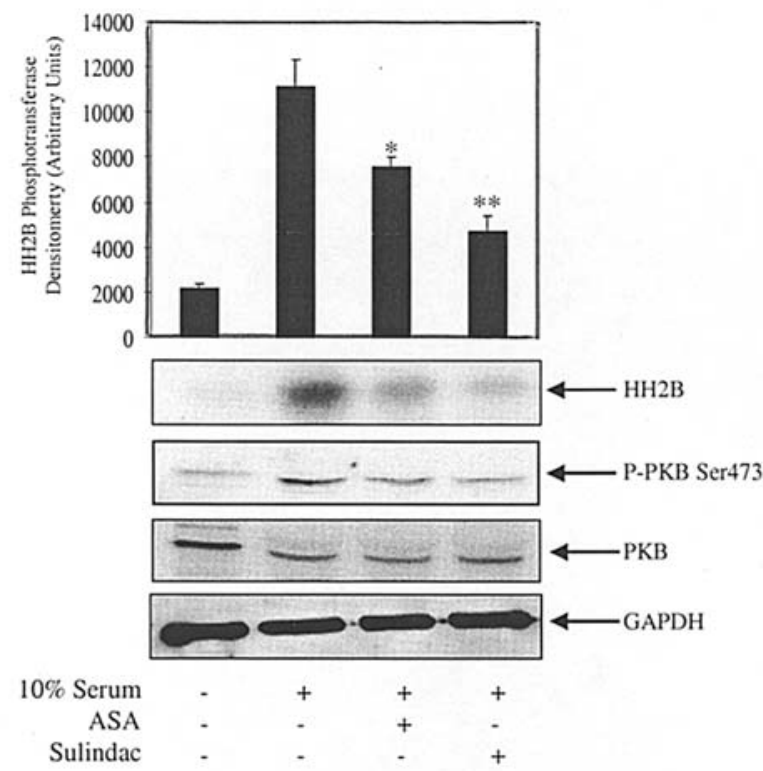

B

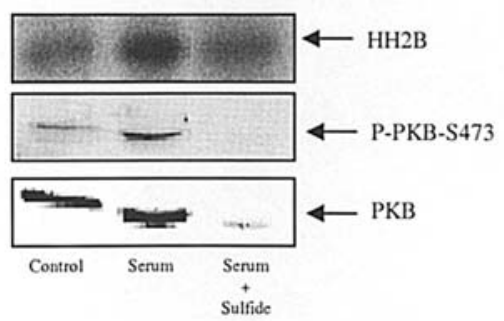

Figure 2. NSAIDs inhibit the serum-induced activation of PKB in vivo. A, DLD-1 cells were treated with ASA $(5 \mathrm{mM})$, sulindac $(1 \mathrm{mM})$ or sulindac sulfide $(100 \mu \mathrm{M})$ as outlined in the Materials and methods. Upper panel, PKB immunoprecipitation and immune complex kinase assays. Lower panels, representative HH2B autoradiogram $\left({ }^{*} \mathrm{p}<0.01,{ }^{* *} \mathrm{p}<0.003\right)$. Whole cell lysates were prepared from DLD-1 cells treated as outline above and blotted with the respective antibodies. The HH2B phosphorylation status was quantified by densitometry (upper panel); the PKB Ser473 immunoblot further depicts these changes. The blot was later stripped and immunoblotted with both PKB and GAPDH to ensure equal protein loading. $\mathrm{B}$, Whole cell extracts were prepared from DLD-1 cells that were treated with either sulindac $(1 \mathrm{mM})$ or sulindac sulfide $(100 \mu \mathrm{M})$, resolved on a $10 \%$ SDS-polyacrylamide gel and immunoblotted with the respective antibodies (SS, serum stimulated). Similar results were obtained on at least 3 independent occasions.

To validate our in vitro findings, we wanted to explore whether these agents could influence the biochemical activity of PKB in vivo. We have previously shown that both sulindac and aspirin (ASA) can inhibit ILK activity in vivo. In order to characterize the effects of these agents on PKB, we performed immune-complex PKB protein kinase assays on lysates prepared from DLD-1 cells that were treated with either ASA (5 mM), sulindac $(1 \mathrm{mM})$ or sulindac sulfide $(100 \mu \mathrm{M})$. The results indicated that all 3 agents inhibited the serum-induced activation of $\mathrm{PKB}$, which is represented by the changes in Histone H2B phosphorylation (Fig. 2). Furthermore, it was determined that changes in the biochemical activity of PKB reflected changes in the Ser473 phosphorylation status. The levels of GAPDH were examined to control for protein loading.
In the case of sulindac sulfide, the resulting decrease in Histone $\mathrm{H} 2 \mathrm{~B}$ phosphorylation was determined to be attributable to changes in relative protein levels (Fig. 2B).

Taken together, there appear to be two distinct mechanisms by which sulindac and sulindac sulfide, regulate PKB activity in vivo, one involves a direct inhibition of the kinase whereas the other is due to changes in the levels of expression of the protein kinase itself.

Influence of PI3-kinase pathway members on NSAID mediated cell death. To determine whether PKB could influence cell death in response to NSAIDs, we made use of the fusion construct containing $\mathrm{PKB}$ and a mutated estrogen receptorbinding domain (PKB-ER) that specifically responds to 4hydroxytamoxifen (27), which was introduced by retroviral infection into MC/9 cells. Stimulation of these cells with 4-HT results in the rapid activation of PKB kinase activity; this activation coincides with phosphorylation of PKB-ER at its two activating sites.

The results from these studies indicated that overexpression of the PKB fusion protein alone has no influence on cell survival, however when the conditionally active exogenous PKB is activated with 4-HT, a pro-survival effect is observed in response to sulindac (Fig. 3A). Specifically, treatment with $1 \mathrm{mM}$ sulindac in the absence of 4-HT resulted in significant apoptotic cell death as indicated by a $50.8 \%$ sub-diploid population. This is strikingly reduced to $14.5 \%$ in the presence of 4-HT. This is in sharp contrast to the effects observed with sulindac sulfide. Conditional activation of PKB had no effect on sulindac sulfide mediated apoptosis. In the absence of 4-HT, $63.4 \%$ of the population exhibited a sub-diploid content whereas $61.4 \%$ contained this DNA profile in the presence of the stimulus.

To corroborate these findings, we transiently transfected HEK293 cells with either wild-type PKB or the empty vector. The HEK293 cell line was chosen for the relative ease of transfection. The data demonstrated that overexpression of PKB attenuated sulindac-induced cell death. No protective effects were observed with the metabolic metabolite, sulindac sulfide (Fig. 3B).

Taken together, and in agreement with the biochemical data, it was concluded that two distinct mechanisms exist by which the pro-form and the metabolic metabolite of sulindac elicit their growth suppressive/antineoplastic effects. One appears to involve the inhibition of PKB activity while the other likely involves a mechanism, which leads to a decrease in $\mathrm{PKB}$ protein expression.

Effects of sulindac sulfide on pathways regulating cell death. There is a large body of evidence supporting the notion that standard chemotherapeutic agents elicit their tumor regressing properties through either the death receptor pathway, at the level of the mitochondria or even cross talk between the two pathways (29-31). As the effector limb of apoptosis relies on caspase activation, evaluation of pro-caspase- 3 expression was performed following treatment with sulindac or its two metabolites and compared to the Cox-2 specific inhibitor NS-398. The results revealed that sulindac sulfide, amongst the panel of drugs, was the only agent that dramatically reduced the levels of pro-caspase- 3 at the $24 \mathrm{~h}$ time-point (Fig. 4A). 
A

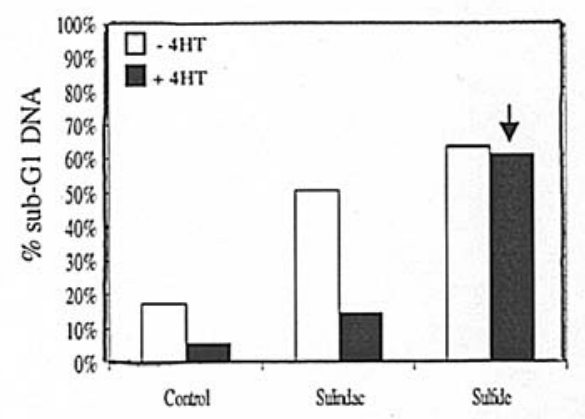

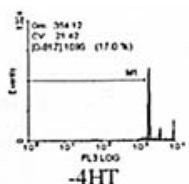

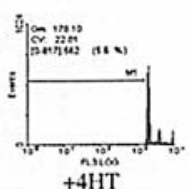

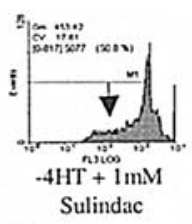

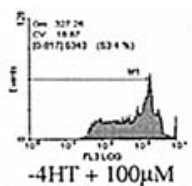

Sulfide
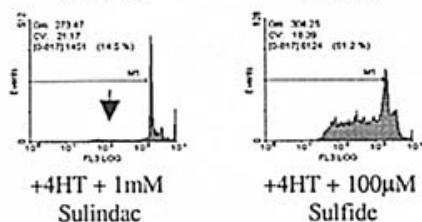

Sulfide

B
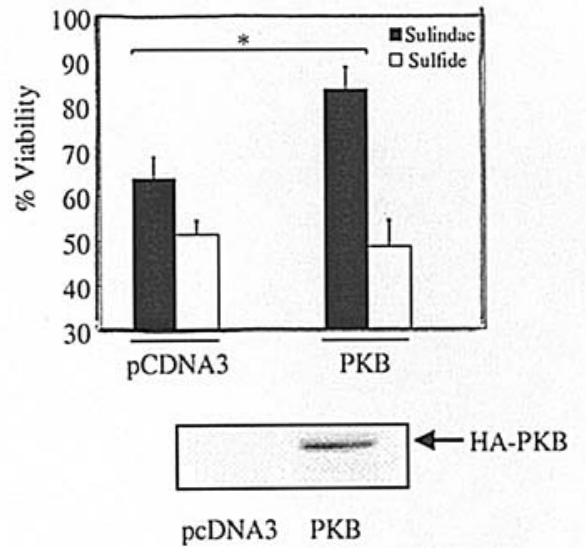

Figure 3. Influence of PI3-kinase pathway members on NSAID mediated cell death. A, MC/9-PKB-ER cells were treated with either sulindac (1 mM) or sulindac sulfide $(100 \mu \mathrm{M})$ in the presence or absence of 4-hydroxytamoxifen (4-HT) as outlined in the Materials and methods. The cells were then harvested and stain with propidium iodide (PI) stain and analyzed by flow cytometry. The extent of apoptosis was based upon the staining of sub-diploid DNA, with numbers in each panel representing the \% of cells with fluorescence intensity below the level of the G1 peak. The vertical axis indicates the number of events on a linear scale and the horizontal axis indicates the relative fluorescence on a log scale (same scale in all panels). The results from these experiments are represented by a bar chart (upper panel) and by the representative histograms. B, Hek293 cells were transiently transfected with either the wild-type PKB or the empty vector and treated as outlined above. The data are represented as a $\%$ change in the absorbance of the treated cells versus the untreated group $\left({ }^{*} \mathrm{p}<0.005\right)$. Similar results were obtained on 3 independent occasions.

At $100 \mu \mathrm{M}$ there was a dramatic reduction in the levels of pro-caspase-3, which coincided with the appearance of the cleaved form of PARP (Fig. 4B). It is worth noting that a cleaved PARP band was also detected when the cells were treated with $50 \mu \mathrm{M}$ sulindac sulfide, but to a lesser extent. PARP cleavage is indicative of caspase- 3 activation.

It is well established that there are two main forms of apoptosis. The activation of caspase- 9 serves as a marker for mitochondrial-mediated cell death whereas the activation of caspase- 8 represents death receptor-dependent cell death. Although others have reported that treatment with sulindac sulfide results in the activation of either caspase- 8 or caspase- 9 $(32,33)$, it is not well established whether the activation of these two pathways are linked in this system. To investigate the mechanism(s) by which sulindac sulfide causes apoptosis in our system, we examined the temporal activation of both caspase- 8 and caspase-9 as well as the common downstream target, caspase-3. Strikingly, the data revealed that both caspase- 8 and caspase- 9 were robustly activated within approximately 5 min of the initial exposure to sulindac sulfide and that the activation was sustained throughout the duration of the experiment (Fig. 4C). Caspase-3 activity appeared to parallel the activation of both caspase- 8 and caspase-9 (although the amplitude was reduced). By 10 min, there was almost a 2-fold increase in the activity; this activity was sustained throughout the time course.

The effects of sulindac sulfide upon the activation of these two pathways were further corroborated by the immunoblots examining the relative expression of the pro-caspase- 8 and pro-caspase-9 as well as the pro- and cleaved forms of caspase-3 (Fig. 4D). The data indicated that treatment with sulindac sulfide results in the simultaneous activation of both caspase- 8 and caspase- 9 . Treatment with sulindac at similar time-points had no effect on the activity levels of the respective caspases (data not shown).

Sulindac-mediated caspase-9 activation is a secondary event. Recent evidence supports the notion that cells can be stimulated to undergo apoptosis through mechanisms independent of the cellular caspases or that the activation of these enzymes occurs as a secondary event (34-37). As sulindac did not modulate the levels of the pro-caspase- 3 protein at the indicated timepoint (Fig. 4A), we wanted to investigate whether this agent could influence the activities of caspase- 8 , caspase- 9 and caspase-3 at later time-points. The data indicated that following 24-h treatment with sulindac, there was approximately a 2-fold 
A

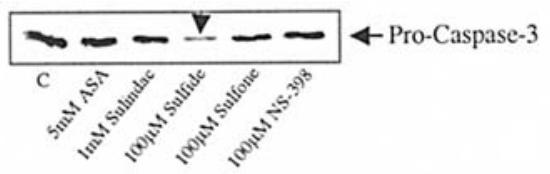

B

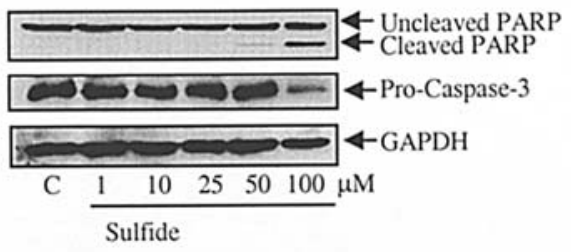

C
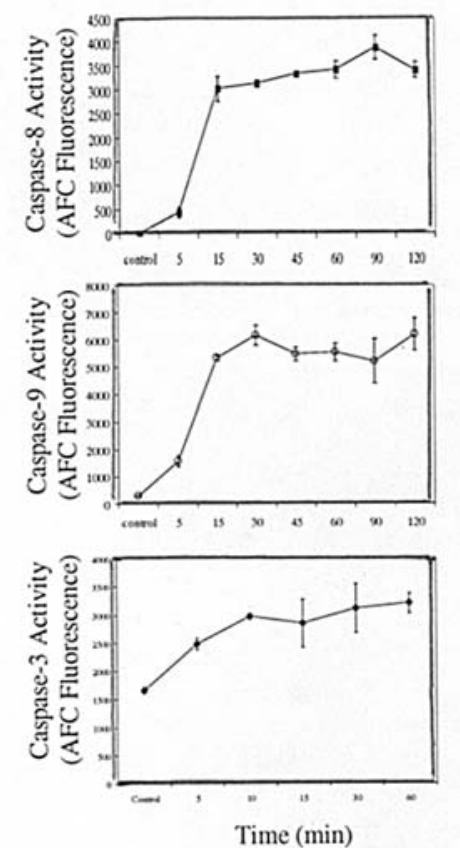

D

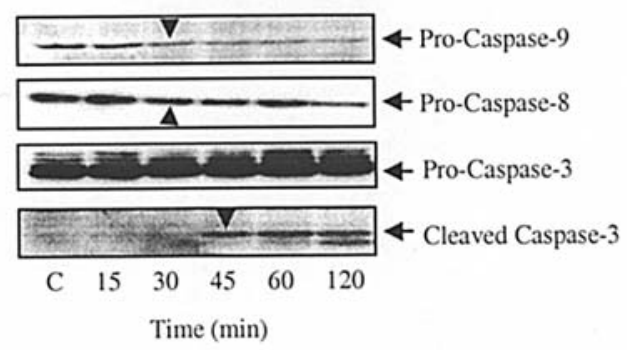

Figure 4. Effects of NSAIDs on pathways regulating cell death. A, Whole cell lysates were prepared from DLD-1 cells that were treated with the indicated NSAIDs as outlined in the experimental procedures, run on a $10 \%$ SDS-polyacrylamide gel and immunoblotted with anti-caspase-3. B, Whole cell lysates were prepared from a dose escalation study with sulindac sulfide. Thirty $\mu \mathrm{g}$ of protein was resolved by SDS-PAGE and blotted with the respective antibodies. The blots were stripped and re-probed with GAPDH to control for protein loading. C, Whole cell lysates were prepared from serum-starved cells that were treated with sulindac sulfide for the indicated time-points and evaluated for caspase-8, caspase-9 and caspase-3 activity as outlined in the experimental procedures. D, DLD-1 lysates were prepared as outlined above and immunoblotted with the respective antibodies. Both the anti-capase- 8 and caspase- 9 antibodies detect the proform of the enzyme while the anti-caspase- 3 detects both the pro- and cleaved forms of caspase-3. Similar results were obtained in three separate experiments.

increase in caspase-9 activity; this activity was sustained throughout (Fig. 5). The activity of caspase-9 appeared to

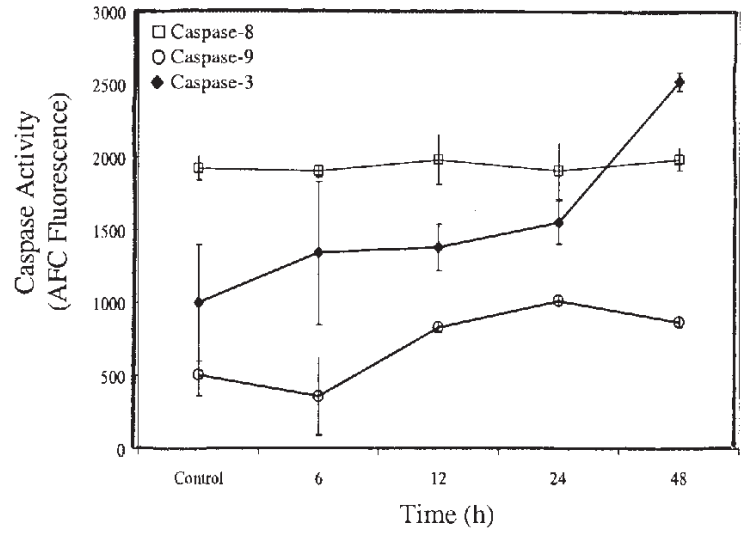

Figure 5. Sulindac-mediated caspase activation is a secondary event. Whole cell lysates were prepared from serum-starved cells that were treated with sulindac for the indicated time-points and evaluated for caspase- 8 , caspase- 9 and caspase- 3 activity as outlined in the Materials and methods.

parallel the activation of caspase-3. By $48 \mathrm{~h}$, there was approximately a 2.5 -fold effect with respect to the control. It is worth noting, that there was no activity directed towards the IETD-fluorogenic substrate, which is indicative of caspase-8 activity in response to sulindac at any of the time-points thus ruling out a potential role for the death receptor pathway in sulindac-induced apoptosis. These findings imply that sulindac, as opposed to sulindac sulfide, likely only influences mitochondrial membrane integrity, which subsequently results in the activation of caspase-9. Equally, the observation that PKB can prevent sulindac-induced cell death implies that PKB must influence mitochondrial integrity. This is in agreement with evidence indicating PKB can prevent cytochrome $\mathrm{c}$ release $(38,39)$.

Interdependence of cellular caspase networks in sulindac sulfide-mediated apoptosis. In the preceding section, we demonstrated both by caspase-activity and immunoblot analysis, that administration of sulindac sulfide resulted in the dual activation of both caspase- 8 and -9 , with almost simultaneous activation of caspase- 3 . To validate these preliminary findings, we evaluated the effects of both the caspase- 8 (z-IETD) and caspase-9 (z-LEHD) inhibitors alone or in combination on drug-mediated alteration in cellular viability. The data from these studies indicated that both of the inhibitors dramatically attenuated sulindac sulfide-mediated apoptosis (Fig. 6A), as well as morphologically (Fig. 6A, panels on right).

To delineate whether the activation of caspase- 8 and caspase-9 were interdependent upon one another, we specifically examined the influence of either of the caspase inhibitors on the activation of both caspase- 8 and caspase- 9 following $30-\mathrm{min}$ exposure to sulindac sulfide. The data revealed that pre-treatment with either of the caspase inhibitors (z-IETD or z-LEHD) attenuated the activation of the respective caspases. Specifically, $1 \mathrm{~h}$ pre-treatment with the caspase- 8 inhibitor (z-IETD) inhibited the sulindac sulfide-induced activation of both caspase- 8 and caspase- 9 ; the activity levels were reduced below the control in both instances (Fig. 6B). Similar results were obtained when the cells were pre-treated with the caspase-9 inhibitor (z-LEHD). 
A
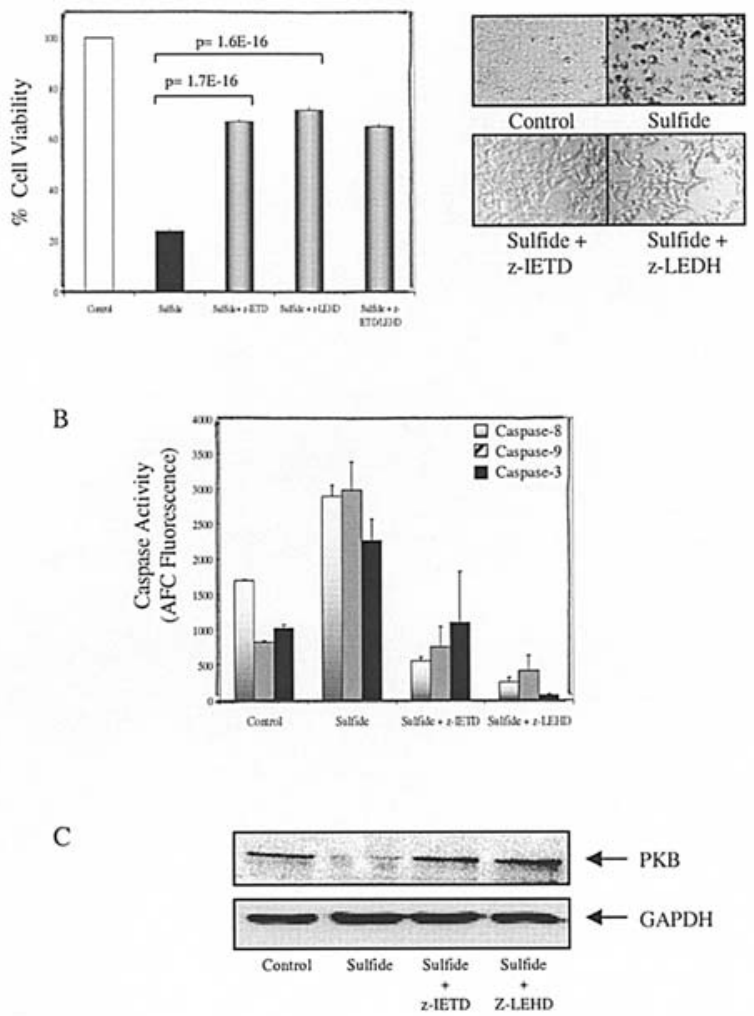

Figure 6. Treatment with caspase inbibitors blunts sulfide-mediated PKB cleavage. A, The HCT-116 cell line was pre-treated with either z-IETD, zLEHD alone or in combination for up to $1 \mathrm{~h}$ and then incubated with sulindac sulfide for $24 \mathrm{~h}$. Viability was measured as outlined above. Photomicrographs of HCT-116 cell line treated as outlined in B. B, Whole cell lysates were prepared from serum-starved cells that were pre-treated with either z-IETD or z-LEHD for up to $1 \mathrm{~h}$ and then exposed to sulindac sulfide for $0.5 \mathrm{~h}$ and evaluated for caspase- 8 , caspase- 9 and caspase- 3 activity as outlined in the Materials and methods. C, DLD- 1 cells were pre-treated with either the caspase-8 (z-IETD) or the caspase-9 (z-LEHD) up to $1 \mathrm{~h}$ and then exposed to sulindac sulfide for $0.5 \mathrm{~h}$. All experiments were performed in triplicate.

Treatment with caspase inhibitors blunts sulfide-mediated $P K B$ cleavage. We observed a dramatic decrease in the levels of PKB protein upon treatment with sulindac sulfide (Fig. 2). As sulindac sulfide has been previously reported to cause apoptosis, we postulated that this reduction in $\mathrm{PKB}$ protein expression is likely a consequence of the commitment of the cell to undergo apoptosis. In this regard, PKB has been reported to be a target of caspase-3 (12).

To validate whether PKB was susceptible to sulindac sulfide-mediated caspase cleavage, we pre-treated the DLD-1 cell line with either the caspase- 8 or caspase-9 inhibitor (zIETD or z-LEHD) and exposed the cells with sulindac sulfide. The data demonstrated that pre-treatment with either of the caspase inhibitors attenuated the reduction in the levels of the PKB protein (Fig. 6C). Caspase-dependent cleavage of PKB has been previously reported to coincide with a decrease in the enzymatic activity of the respective kinase (40).

\section{Discussion}

Aspirin, a non-steroidal anti-inflammatory agent, provides a beneficial effect in clinical situations including heart disease, rheumatoid arthritis and cancer (41-43). The mechanism by which this and other similar drugs mediate their effects is thought to involve the inhibition of Cox function $(44,45)$. However, recent scientific data suggest that alternative mechanisms could be involved in eliciting the effects of these drugs. In particular, administration of NS-398, a Cox-2 specific inhibitor, has been shown to promote apoptosis in a caspase-9dependent manner $(46,47)$. Another study demonstrated that sulindac sulfide is able to promote apoptosis through a death receptor-dependent mechanism (32). In addition to this, sulindac has been shown to inhibit the pro-survival $\mathrm{NF}-\kappa \mathrm{B}$ signaling module at the level of IKK (19). Furthermore, these agents have also been shown to inhibit PPARd (48), alter the Bax to $\mathrm{Bcl}-\mathrm{X}_{\mathrm{L}}$ ratio (18) and promote ceramide generation (49). Of special interest, celecoxib, a Cox-2 specific inhibitor, has been shown to inhibit the biochemical activity of protein kinase B in a PI3-kinase-independent manner (50). More recently, this Cox-2 specific inhibitor was also reported to inhibit PDK1, the kinase that regulates Thr-308 phosphorylation on PKB (51).

In the present report, we provide novel evidence that sulindac and sulindac sulfide differentially converge on one of the major anti-apoptotic pathways, the PI3-kinase/PKB pathway. Specifically, we demonstrate that administration of either sulindac or sulindac sulfide results in a decrease in the serum-induced phosphorylation of PKB at Ser473. However, we demonstrate that the effects of sulindac sulfide on PKB Ser473 phosphorylation are due to a decrease in $\mathrm{PKB}$ protein expression rather than an effect on one of the upstream activating kinases. This decrease in PKB protein expression was determined to be due to the dramatic early activation of the cellular caspases. Additionally, we demonstrate that both aspirin and sulindac inhibit PKB biochemical activity in an immune complex kinase assay. Based on our previous findings, which indicated that ILK activity is modulated by these agents, we believe that this effect on Ser473 phosphorylation could be mediated through ILK itself (20). However, one cannot rule out that this is a direct effect based upon the inhibitory effects of sulindac on in vitro PKB activity.

Although it is well established that the PI3-kinase/PKB pathway plays a critical role in regulating apoptosis; it is not clear how this pathway provides a survival effect or at what level. Here we demonstrate both by transient and stable overexpression that PKB abrogates the effects of sulindac but not sulindac sulfide on apoptosis. In addition to this, we demonstrate that treatment with sulindac sulfide leads to a very early robust activation of both of the downstream caspases involved in the death receptor and mitochondrial pathways. The latter result is in agreement with a previous report in which it was demonstrated that sulindac sulfide promotes cell death mainly through a death receptor (DR)-5/caspase-8dependent mechanism (32). Our results add to these findings, by demonstrating that sulindac sulfide mediates its apoptotic effects through both caspase- 8 and -9 , which likely mediate their effects through a common downstream effector caspase. This conclusion is supported by the robust amplitudes of sulindac sulfide-induced caspase- 8 and -9 activation; attenuation of both of their respective activities, with either of the caspase-specific 8 or 9 inhibitors; and finally, the reduction in sulindac sulfide-induced cytotoxicity observed by using either inhibitor. 
In this report, we also demonstrate that the effects of sulindac on apoptosis, specifically the activation of caspase- 9 and caspase-3, are consequent upon the inhibition of PKB. It is quite possible that sulindac elicits its effects by disrupting cell metabolism through a PKB-dependent mechanism, which would involve compromising mitochondrial integrity. Previous work has implicated PKB in the modulation of mitochondriaassociated hexokinase activity (38), which has been linked to the inhibition of cytochrome $\mathrm{C}$ release. Furthermore, we exclude an effect of the death-receptor pathway in sulindacmediated apoptosis.

In conclusion, we provide compelling evidence that there are two distinct mechanisms by which sulindac and sulindac sulfide elicit their anti-neoplastic properties. We conclude that these findings may be of medical importance, as a number of the components in the PI3-kinase pathway have been demonstrated to be dysregulated in human cancers (52-54). Therefore, based upon the observation that overexpression of an integral component in the PI3-kinase pathway, PKB, had no effect on sulindac sulfide-induced cell death, whereas the effects of sulindac were dramatically blunted, we propose that treatment with the former may be an effective adjuvant therapy.

\section{Acknowledgements}

This work was supported in part by grants from the Cancer Research Society and the Canadian Society for Intestinal Research to B.S., and from the National Cancer Institute of Canada and the Cancer Research Society to V.D.

\section{References}

1. Haanen C and Vermes I: Apoptosis: programmed cell death in fetal development. Eur J Obstet Gynecol Reprod Biol 64: 129-133, 1996

2. Brill A, Torchinsky A, Carp H and Toder V: The role of apoptosis in normal and abnormal embryonic development. J Assist Reprod Genet 16: 512-519, 1999.

3. Grossmann J: Molecular mechanisms of 'detachment-induced apoptosis-Anoikis'. Apoptosis 7: 247-260, 2002.

4. Mullauer L, Gruber P, Sebinger D, Buch J, Wohlfart S and Chott A: Mutations in apoptosis genes: a pathogenetic factor for human disease. Mutat Res 488: 211-231, 2001.

5. Warner HR: Apoptosis: a two-edged sword in aging. Anticancer Res 19B: 2837-2842, 1999.

6. Zimmermann J, Lamerant N, Grossenbacher R and Furst P: Proteasome- and p38-dependent regulation of ERK3 expression. J Biol Chem 276: 10759-10766, 2001.

7. Schmitz I, Kirchhoff S and Krammer PH: Regulation of death receptor-mediated apoptosis pathways. Int J Biochem Cell Biol 32: 1123-1136, 2000.

8. Zimmermann KC and Green DR: How cells die: apoptosis pathways. J Allergy Clin Immunol 108 (Suppl. 4): S99-S103, 2001.

9. Green DR and Reed JC: Mitochondria and apoptosis. Science 281: 1309-1312, 1998.

10. Cai J, Yang J and Jones DP: Mitochondrial control of apoptosis: the role of cytochrome c. Biochim Biophys Acta 1366: 139-149, 1998.

11. Browne SJ, MacFarlane M, Cohen GM and Paraskeva C: The adenomatous polyposis coli protein and retinoblastoma protein are cleaved early in apoptosis and are potential substrates for caspases. Cell Death Differ 5: 206-213, 1998.

12. Bachelder RE, Ribick MJ, Marchetti A, Falcioni R, Soddu S, Davis KR and Mercurio AM: p53 inhibits alpha 6 beta 4 integrin survival signaling by promoting the caspase 3 dependent cleavage of AKT/PKB. J Cell Biol 147: 1063-1072, 1999.
13. Steinhusen U, Badock V, Bauer A, Behrens J, Wittman-Liebold B, Dorken B and Bommert K: Apoptosis-induced cleavage of beta-catenin by caspase-3 results in proteolytic fragments with reduced transactivation potential. J Biol Chem 275: 16345-16353, 2000.

14. Piazza GA, Alberts DS, Hixson LJ, et al: Sulindac sulfone inhibits azoxymethane-induced colon carcinogenesis in rats without reducing prostaglandin levels. Cancer Res 57: 2909$2915,1997$.

15. Waddell WR and Loughry RW: Sulindac for polyposis of the colon. J Surg Oncol 24: 83-87, 1983

16. Labayle D, Fischer D, Vielh P, et al: Sulindac causes regression of rectal polyps in familial adenomatous polyposis. Gastroenterology 101: 635-639, 1991.

17. Boolbol SK, Dannenberg AJ, Chadburn A, et al: Cyclooxygenase- 2 over-expression and tumor formation are blocked by sulindac in a murine model of familial adenomatous polyposis. Cancer Res 56: 2556-2560, 1996.

18. Zhang L, Yu J, Park BH, Kinzler KW and Vogelstein B: Role of BAX in the apoptotic response to anticancer agents. Science 290: 989-992, 2000.

19. Yamamoto Y, Yin MJ, Lin KM and Gaynor RB: Sulindac inhibits activation of the NF-kappaB pathway. J Biol Chem 274: 27307-27314, 1999.

20. Marotta A, Tan C, Gray V, Malik S, Gallinger S, Sanghera J, Dupuis B, Owen D, Dedhar S and Salh B: Dysregulation of integrin-linked kinase (ILK) signaling in colonic polyposis. Oncogene 20: 6250-6257, 2001.

21. Deguchi A, Thompson WJ and Weinstein IB: Activation of protein kinase $\mathrm{G}$ is sufficient to induce apoptosis and inhibit cell migration in colon cancer cells. Cancer Res 64: 3966-3973, 2004.

22. Hannigan G, Troussard AA and Dedhar S: Integrin-linked kinase: a cancer therapeutic target unique among its ILK. Nat Rev Cancer 5 51-63, 2005.

23. Vanhaesebroeck B and Alessi DR: The PI3K-PDK1 connection: more than just a road to PKB. Biochem J 346: 561-576, 2000.

24. Tang ED, Nunez G, Barr FG and Guan KL: Negative regulation of the forkhead transcription factor FKHR by Akt. J Biol Chem 274: 16741-16746, 1999.

25. Del Peso L, Gonzalez VM, Hernandez R, Barr FG and Nunez G: Regulation of the forkhead transcription factor FKHR, but not the PAX3-FKHR fusion protein, by the serine/threonine kinase Akt. Oncogene 18: 7328-7333, 1999.

26. Brunet A, Bonni A, Zigmond MJ, et al: Akt promotes cell survival by phosphorylating and inhibiting a Forkhead transcription factor. Cell 96: 857-868, 1999.

27. Kohn AD, Barthel A, Kovacina KS, et al: Construction and character-ization of a conditionally active version of the serine/ threonine kinase Akt. J Biol Chem 273: 11937-11943, 1998.

28. Vanhaesebroeck B and Waterfield MD: Signaling by distinct classes of phosphoinositide 3-kinases. Exp Cell Res 253: 239-254, 1999.

29. Milner AE, Palmer DH, Hodgkin EA, Eliopoulos AG, Knox PG, Poole CJ, Kerr DJ and Young LS: Induction of apoptosis by chemotherapeutic drugs: the role of FADD in activation of caspase- 8 and synergy with death receptor ligands in ovarian carcinoma cells. Cell Death Differ 9: 287-300, 2002.

30. Wu XX, Kakehi Y, Mizutani Y, Lu J, Terachi T and Ogawa O: Activation of caspase- 3 in renal cell carcinoma cells by anthracyclines or 5-fluorouracil. Int J Oncol 19: 19-24, 2001.

31. Ferreira CG, Span SW, Peters GJ, Kruyt FA and Giaccone G: Chemotherapy triggers apoptosis in a caspase-8-dependent and mitochondria-controlled manner in the non-small cell lung cancer cell line NCI-H460. Cancer Res 60: 7133-7141, 2000 .

32. Huang Y, He Q, Hillman MJ, Rong R and Sheikh MS: Sulindac sulfide-induced apoptosis involves death receptor 5 and the caspase 8-dependent pathway in human colon and prostate cancer cells. Cancer Res 61: 6918-6924, 2001.

33. Tang X, Sun YJ, Half E, Kuo MT and Sinicrope F: Cyclooxygenase- 2 overexpression inhibits death receptor 5 expression and confers resistance to tumor necrosis factor-related apoptosisinducing ligand-induced apoptosis in human colon cancer cells. Cancer Res 62: 4903-4908, 2002.

34. Huisman C, Ferreira CG, Broker LE, Rodriguez JA, Smit EF, Postmus PE, Kruyt FA and Giaccone G: Paclitaxel triggers cell death primarily via caspase-independent routes in the non-small cell lung cancer cell line NCI-H460. Clin Cancer Res 8: 596-606, 2002 . 
35. Shankar SL, Mani S, O'Guin KN, Kandimalla ER, Agrawal S and Shafit-Zagardo B: Survivin inhibition induces human neural tumor cell death through caspase-independent and -dependent pathways. J Neurochem 79: 426-436, 2001.

36. Bidere N and Senik A: Caspase-independent apoptotic pathways in T lymphocytes: a minireview. Apoptosis 6: 371-375, 2001

37. Belmokhtar CA, Hillion J and Segal-Bendirdjian E: Staurosporine induces apoptosis through both caspase-dependent and caspaseindependent mechanisms. Oncogene 20: 3354-3362, 2001.

38. Gottlob K, Majewski N, Kennedy S, Kandel E, Robey RB and Hay N: Inhibition of early apoptotic events by Akt/PKB is dependent on the first committed step of glycolysis and mitochondrial hexokinase. Genes Dev 15: 1406-1418, 2001.

39. Hundal RS, Gomez-Munoz A, Kong JY, Salh BS, Marotta A, Duronio V and Steinbrecher UP: Oxidized low density lipoprotein inhibits macrophage apoptosis by blocking ceramide generation, thereby maintaining protein kinase $\mathrm{B}$ activation and $\mathrm{Bcl}-\mathrm{XL}$ levels. J Biol Chem 278: 24399-24408, 2003.

40. Rokudai S, Fujita N, Hashimoto Y and Tsuruo T: Cleavage and inactivation of antiapoptotic Akt/PKB by caspases during apoptosis. J Cell Physiol 182: 290-296, 2000.

41. DuBois RN and Smalley WE: Cyclooxygenase, NSAIDs, and colorectal cancer. J Gastroenterol 31: 898-906, 1996.

42. Smith WL, De Witt DL and Garavito RM: Cyclooxygenases: structural, cellular, and molecular biology. Annu Rev Biochem 69: $145-182,2000$

43. Smalley WE and DuBois RN: Colorectal cancer and nonsteroidal anti-inflammatory drugs. Adv Pharmacol 39: 1-20, 1997.

44. Oshima M, Dinchuk JE, Kargman SL, Oshima H, Hancock B, Kwong E, Trzaskos JM, Evans JF and Taketo MM: Suppression of intestinal polyposis in Apc delta716 knockout mice by inhibition of cyclooxygenase 2 (COX-2). Cell 87: 803-809, 1996.

45. Hansen-Petrik MB, McEntee MF, Jull B, Shi H, Zemel MB and Whelan J: Prostaglandin E(2) protects intestinal tumors from nonsteroidal anti-inflammatory drug-induced regression in Apc(Min/+) mice. Cancer Res 62: 403-408, 2002.
46. Li M, Wu X and Xu XC: Induction of apoptosis by cyclooxygenase-2 inhibitor NS398 through a cytochrome C-dependent pathway in esophageal cancer cells. Int J Cancer 93: 218-223, 2001.

47. Li M, Wu X and Xu XC: Induction of apoptosis in colon cancer cells by cyclooxygenase-2 inhibitor NS398 through a cytochrome c-dependent pathway. Clin Cancer Res 7: 1010-1016, 2001.

48. He TC, Chan TA, Vogelstein B and Kinzler KW: PPARdelta is an APC-regulated target of nonsteroidal anti-inflammatory drugs. Cell 99: 335-345, 1999.

49. Chan TA, Morin PJ, Vogelstein B and Kinzler KW: Mechanisms underlying nonsteroidal antiinflammatory drug-mediated apoptosis Proc Natl Acad Sci USA 95: 681-686, 1998.

50. Hsu AL, Ching TT, Wang DS, Song X, Rangnekar VM and Chen CS: The cyclooxygenase-2 inhibitor celecoxib induces apoptosis by blocking Akt activation in human prostate cancer cells independently of Bcl-2. J Biol Chem 275: 11397-11403, 2000 .

51. Arico S, Pattingre S, Bauvy C, Gane P, Barbat A, Codogno P and Ogier-Denis E: Celecoxib induces apoptosis by inhibiting 3phosphoinositide-dependent protein kinase-1 activity in the human colon cancer HT-29 cell line. J Biol Chem 277: 27613-27621, 2002.

52. Brognard J, Clark AS, Ni Y and Dennis PA: Akt/protein kinase B is constitutively active in non-small cell lung cancer cells and promotes cellular survival and resistance to chemotherapy and radiation. Cancer Res 61: 3986-3997, 2001.

53. Graff JR, Konicek BW, McNulty AM, et al: Increased AKT activity contributes to prostate cancer progression by dramatically accelerating prostate tumor growth and diminishing p27Kip1 expression. J Biol Chem 275: 24500-24505, 2000.

54. Salh B, Marotta A, Wagey R, Sayed M and Pelech S: Dysregulation of phosphatidylinositol 3-kinase and downstream effectors in human breast cancer. Int J Cancer 98: 148-154, 2002. 